\title{
ODKRYWANIE MIKROFIZYKI \\ NIERÓWNOŚCI
}

MACIEJ GDULA

I PRZEMYSŁAW SADURA [RED.],

STYLE ŻYCIA I PORZĄDEK

KLASOWY W POLSCE

Małgorzata Jacyno

Uniwersytet Warszawski

Główną tezą książki jest to, że kultury klasowe należy pojmować jako rywalizujące uniwersalności. W tej tezie Autorzy słusznie eksponuja istotny rys podejścia Pierre’a Bourdieu, a mianowicie relacyjność treści i zasad konstytuujących kultury klasowe. Koncepcja „rywalizujących uniwersalności” ma być również w zamierzeniu Autorów próbą syntetycznego odniesienia się do dorobku Bourdieu i znalezienia jednej formuły interpretacyjnej dla jego prac z końca lat siedemdziesiątych i dziewięćdziesiątych. Maciej Gdula i Przemysław Sadura mają na uwadze głównie ostatnie wypowiedzi Bourdieu, w których pojawia się myśl o możliwych pożytkach z odwołań do uniwersalnych wartości. Odwołania te, jeśli maja stać się prawomocne, muszą być po części przynajmniej realizowane w praktyce, co z kolei może być ograniczeniem dominacji. Myśl tę Bourdieu rozwijał w kontekście zróżnicowania pól, ale nie odniósł jej, jak można przeczytać w otwierających książkę rozdziałach, do problemu dystansów klasowych. Rozwinięciem głównej tezy zdają się bogate ilustracje relacyjności kultur klasowych w Polsce oraz pojawiające się w kilku rozdziałach książki uwagi na temat bliskości klasy wyższej i klasy średniej, a także klasy wyższej i klasy ludowej oraz możliwych sojuszy pomiędzy nimi.

W zaproponowanej przez Autorów koncepcji „rywalizujących uniwersalności” można zobaczyć ciekawa próbę zmierzenia się z kwestią ,idealizmu” francuskiego socjologa zmarłego dekadę temu. „Idealizm” Bourdieu 
przejawiał się w przekonaniu, że walki toczące się w życiu społecznym będą nabierały coraz bardziej symbolicznego charakteru. Dobra zapowiedź tej prognozy można odnaleźć w Psychologii nieśniadomości Zygmunta Freuda. Freud pisze: „Walka wrząca w niższych warstwach nie doszła do końca za sprawą szybkiej sublimacji i szybkiego utożsamienia - trwa ona nadal niczym na obrazie Kaulbacha, przedstawiającym, w jaki sposób bitwa z Hunami kontynuowana jest w wyższych regionach". W przypisie zaś znajdujemy dopowiedzenie, że polegli wojownicy „poszli do nieba” i tam dalej oddają się walce, którą rozpoczęli na ziemi. Przeniesienie walk do kulturowego nieba - w sferę symboli - nie sprawia, że tracą one na zaciekłości, ponieważ w grę wchodzą straszliwie wysokie stawki, a mianowicie: racja bytu i tożsamość ludzi.

Przedstawiona powyżej interpretacja w różnych wersjach zdaje się dominująca w amerykańskich studiach kulturowych, abject studies, teorii postkolonialnej oraz w części brytyjskiej socjologii zainteresowanej dystansami społecznymi. Wymienione cztery nurty analiz i badań pokazuja, że kultura wcale nie jest niejako z definicji życzliwa czy przynajmniej bardziej przyjazna ludziom niż na przykład struktura. $Z$ tego powodu wbrew intencjom Autorów możliwość przeniesienia rozstrzygnięć dotyczących pól, także tezy o uniwersalizacji, do koncepcji dystansów klasowych wydaje się bardzo ograniczona. Także dlatego, że wymieniane przez Bourdieu pola (dziennikarskie, edukacyjne, artystyczne, naukowe czy polityczne) to przestrzenie zdominowane przez klasy średnie. Szkoda, że Autorzy, budując swoja perspektywę, konfrontuja się jedynie z kilkoma badaczami polskimi odwołującymi się do niektórych pomysłów Bourdieu, a nie odnoszą się do współczesnych interpretacji inspirowanych jego socjologia i badań realizowanych poza Polską. Odniesienie takie pozwoliłoby Autorom być może na bardziej precyzyjne ustalenie współrzędnych własnego stanowiska i bardziej przekonujące uzasadnienie, dlaczego takie a nie inne praktyki były przedmiotem ich badania. Wybór badanych praktyk - jazda na rowerze, stosunek do zwierząt i stosunek do pracy - jest fascynujący, ale wyjaśnienia dotyczące tego wyboru zawarte we wstępie i w rozdziale pierwszym pozostają niejako zawieszone w próżni.

Wybór przedmiotu badania, a następnie interpretacja materiału, jak możemy przeczytać we wstępie, miały zapobiec egzotyzacji różnic i niebezpieczeństwu ich unieważnienia. Chodzi jednak o to, że mówienie „mysza”, „kupywać” czy niewpuszczanie na wsi za próg domu zwierząt to być może „etnograficzne szczegóły”, za którymi stoja jednak socjologiczne racje. Skazanie kota wiejskiego na to, by całe życie przeżył bezimiennie, 
nie jest być może egzotyczne dla etnografa i socjologa, których misja jest przemierzanie różnych światów i „rozumienie”, ale dla klas wyższej i średniej musi pozostać przejawem barbarzyństwa. Cząstkowe podobieństwa (stosunek do zwierząt czy jeżdżenie na zdezelowanym rowerze) mają w przekonaniu Autorów wskazywać na możliwość sojuszy, prawdopodobieństwo porozumienia między przedstawicielami różnych klas czy słabość granic między kulturami klasowymi. Treści i praktyki charakteryzujące różne kultury klasowe mogą być podobne, a różnice między nimi znikome, jednak kultury w codziennych praktykach ludzi nie są czytane i interpretowane. Tekstualne, „niepraktyczne” odniesienie do różnic kulturowych pozwala zobaczyć wiele spośród nich jako różnice nieistotne, „diakrytyczne”. Doniosłość różnic, nieprzekraczalność barier nie rodzi się z dyskursów przesady czy ideologii, w których znikome różnice są wyolbrzymiane, eskalowane czy egzotyzowane, ale z faktu, że są zakorzenione w odczuciach niechęci, wstrętu i obrzydzenia do tego, co reprezentuje inna oczywistość czy alternatywną uniwersalność.

Problem ten podnoszony jest $\mathrm{w}$ inspirowanych teorią Bourdieu analizach i badaniach koncentrujących się na frakcjach klasy średniej (T. Bennett, L. Adkins, M. Savage, B. Skeggs). Jest to kolejny pominięty w badaniach Autorów wątek, a obecny także w polskich reinterpretacjach koncepcji „wszystkożerności” (T. Szlendak). Nowe interpretacje „wszystkożerności” wskazują na to, że nie dystanse, ale bliskość pozycji wyzwala nowe procesy i staje się dzisiaj powodem zaciekłych walk symbolicznych, które są eufemizowane i redukowane do kwestii „zmieniających się mód” i „taniej rozrywki”, jakiej dostarczaja popularne programy telewizyjne. Podczas gdy Autorzy deklaruja zamiar modyfikacji teorii Bourdieu (w dalszej części recenzji odniosę się do tej kwestii bardziej szczegółowo), dzisiaj powracają jej ortodoksyjne odczytania (B. Skeggs), w których zwraca się uwagę na to, że całkiem tradycyjne, tj. znane zwłaszcza z Dystynkcji (Bourdieu 2005), przedstawienia klasy wyższej i klasy ludowej stanowią o granicach i treści kosmologii klasy średniej, i jej wyobrażeniach dotyczaccych tego, co to znaczy „znaleźć się w niebie” i co to znaczy „znaleźć się w piekle”. Zwłaszcza badania socjologów brytyjskich pokazuja, że ortodoksyjne odczytania Bourdieu pozwalaja prowadzić rzetelne badania i nie skazują badaczy jedynie na poszukiwanie adekwatnej etykiety dla takich czy innych praktyk. Zwracam na to uwage, ponieważ w kilku rozdziałach książki nietrudno natrafić na niedostatki interpretacyjne i zdarza się, że rdzeń komentarza do cytowanych wypowiedzi stanowi przede wszystkim „etykieta” i spostrzeżenie, że są one „typowe” dla tej czy innej klasy. 
Przekornie powiedziałabym, że o wartości recenzowanej książki, wbrew zapowiedziom Autorów, stanowi program ortodoksyjnej lektury teorii Pierre'a Bourdieu. Zawarte w pierwszych partiach pracy zapewnienia o konieczności modyfikacji tej teorii nie znajduja pełnego rozwinięcia, a w każdym razie nie wskazuje się, z czego konieczność takich zmian miałaby wynikać ani na czym konkretnie miałyby polegać. Głównym, krytycznym punktem odniesienia pozostają dla Autorów nie zmiany rzeczywistości czy któraś z tez Bourdieu, ale użytek, jaki robią z nich badacze polscy. Za to teza kluczowa dotycząca możliwych aliansów międzyklasowych, która ma wynikać z próby pogodzenia stanowiska Bourdieu z lat siedemdziesiątych i dziewięćdziesiątych, zostaje obwarowana licznymi zastrzeżeniami (Erbel, Templewicz), a w większości tekstów po prostu jest nieobecna. Krytykowana na początku interpretacja mówiąca o dominacji kapitału kulturowego nad kapitałem ekonomicznym w warunkach polskich realiów przynajmniej po części zostaje zrehabilitowana (Kołodziejska, Hnatiuk). Jakkolwiek nieoczywisty jest - wobec aktualnie prowadzonych badań - wybór badanych praktyk i postaw, to odnoszone są w większości wypadków do „emblematów” klasowych różnic, tak jak je widział Bourdieu (klasie wyższej zostaje przypisana dystynkcja, która bierze się z wolności od determinacji rynkowej. Klasa wyższa „to ludzie, którzy nie szukaja pracy, to ludzie, których szuka praca”. Dyscyplina jest tradycyjnie zarezerwowana dla klasy średniej. Bezceremonialność i rubaszność nazywana jest skłonnością klasy ludowej do familiaryzowania relacji). Struktura całej pracy porządkuje treści w sposób całkiem tradycyjny, charakterystyczny dla socjologii Bourdieu. Przy posiłkowaniu się teoriami autorów tej miary co Bourdieu uwagi o konieczności modyfikacji, dostosowania, korekty itp. sa w socjologii i w naukach społecznych bez mała rytualne. Może warto polemizować z tym rytuałem? Może warto zastanowić się nad jego socjogeneza?

Nie wydaje się, aby ortodoksyjne odczytania socjologii Pierre'a Bourdieu przestały być aktualne. Dzieje się tak głównie z tego powodu, że jej szkolne racjonalizacje - także na studiach socjologicznych - zdają się mieć za ostateczny efekt możliwość wypowiedzenia przez studenta tego, $\dot{z ̇ e}$ pochodzenie determinuje to, jakie ludzie mają wykształcenie. To, że pochodzenie decyduje o zdobytym wykształceniu, nie jest oczywiście ani odkrywcze, ani nie wymaga kosztownych badań. Większość różnic opisanych przez Bourdieu w Dystynkcyi to różnice widoczne gołym okiem. Bez badań widać też, że klasy ludowe nieodmiennie jeżdżą na zdezelowanych rowerach, a według części polskiej klasy średniej lat dziewięćdziesiątych 
górski rower lub samochód terenowy są niezbędne do tego, żeby przedrzeć się przez centrum dużego miasta. Zebrany i zinterpretowany przez Autorów materiał pokazuje za to, jak siermiężne sa popularne i szkolne interpretacje teorii Bourdieu. Zawarte w książce bogate dane z opisów codzienności oraz narracji biograficznych moga raz na zawsze uwolnić czytelnika od orzekania o prostej zależności przykładowo między pochodzeniem i wykształceniem. Nie chodzi bowiem o to, że określone pochodzenie skazuje ludzi na określone wykształcenie. Chodzi o to, że pomiędzy nimi - punktem wyjścia, czyli pochodzeniem, a punktem dojścia, czyli wykształceniem, dzieje się i wydarza zawsze coś, co sprawia, że taka zależność przybiera kształt prawa (por. Bourdieu 2005: 120-124).

Problem nie polega na tym, a w każdym razie nie to stanowi o jego istocie, że pochodzenie z klasy ludowej uniemożliwia zdobycie wykształcenia, ale że niejako po drodze, zanim jakości, czynniki i kryteria ułożą się w żelazne łańcuchy związków przyczynowo-skutkowych, determinacji i praw, wydarza się mikrofizyka codziennych wyborów, pragnień, większych i mniejszych sukcesów i porażek, trawionych szybko i na bieżąco albo przez całe życie. Dobrze ukazują to rozdziały ilustrujące rozmaite wersje „końców świata" związanych z awansem lub deklasacja (Ferenc, Tomaszuk, Rawski, Olko, Gdula). Zgromadzony materiał pokazuje, jak „w terenie”, jakim jest życie ludzkie, działa fabryka nierówności, w czym przejawia się alchemia kapitalizmu, mikrofizyka osobistych dążen, pragnień i możliwości oraz eksploatacja w niebie kultury, gdzie najbardziej zewnętrzne okoliczności zostają zwinięte w poczucie bycia panem lub ofiarą własnej wewnętrzności (Świrek, Strzelecki, Kastory i Lipiński). Właśnie dlatego „ilustracyjność” przedsięwzięcia Autorów wobec socjologii Bourdieu w niczym nie umniejsza wagi ich dokonań. Rozgarnięcie zagęszczeń codziennych, banalnych wydarzeń, zwykłych myśli i spostrzeżeń zwykłych ludzi ukazuje, jak to się dzieje, że precyzyjnie dopasowują się one do siebie lub precyzyjnie konfrontują się ze sobą i dają ostatecznie znany wzór nierówności. Autorom udało się zrealizować postulat denaturalizacji świata społecznego bez oskarżycielskich wskazań i posądzeń o arbitralność takich czy innych treści i praktyk, a przez wydobycie faktu, że nieuchronność determinacji nie zaistniałaby, gdyby nie uprawiane na co dzień przez ludzi mikropolityki wobec innych i wobec siebie. 
Bibliografia:

/// Adkins L., Skeggs B. 2004. Feminism after Bourdieu, Blackwell Publishing, Oxford.

/// Bennett T. i in. 2010. Culture, Class, Distinction, Routledge, LondonNew York.

/// Bourdieu P., Passeron J.-C. 2005. Reprodukcja. Elementy teorii systemu nauczania, tłum. E. Neyman, Wydawnictwo Naukowe PWN, Warszawa.

/// Bourdieu P. 2005. Dystynkcja. Społeczna krytyka władsy sqdzenia, thum. P. Biłos, Wydawnictwo Naukowe SCHOLAR, Warszawa.

/// Freud Z. 2007. Psychologia nieśniadomości, tłum. R. Reszke, Wydawnictwo KR, Warszawa.

/// Gdula M., Sadura P., red. 2012. Style šycia i porzqdek klasony w Polsce, Wydawnictwo Naukowe SCHOLAR, Warszawa.

/// Savage M. 2000. Class Analysis and Social Transformation, Open University Press, Buckingham.

/// Skeggs B. 2004. Class, Self, Culture, Routledge, London-New York.

/// Szlendak T. 2011. Nic? Aktywność kulturalna na wsi i w matych miastach, [w:] Stan $i$ zróżnicowanie kultury wsi i malych miast w Polsce, I. Bukrba-Rylska, red. W. Burszta, Narodowe Centrum Kultury, Warszawa, s. 53-101. 